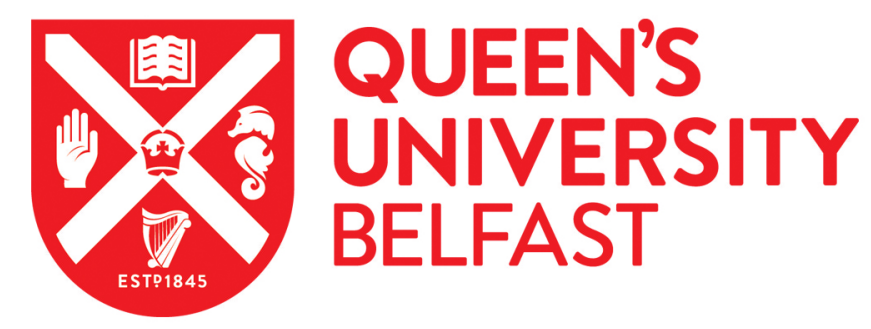

\title{
Psychological adjustment to Type 2 diabetes and relationship quality
}

Dempster, M., McCarthy, T., \& Davies, M. (2011). Psychological adjustment to Type 2 diabetes and relationship quality. Diabetic Medicine, 28(4), 487-492. https://doi.org/10.1111/j.1464-5491.2010.03214.x

\author{
Published in: \\ Diabetic Medicine
}

\section{Document Version:}

Peer reviewed version

\section{Queen's University Belfast - Research Portal:}

Link to publication record in Queen's University Belfast Research Portal

\section{Publisher rights}

Copyright 2011 The Authors. Diabetic Medicine. Diabetes UK

This work is made available online in accordance with the publisher's policies. Please refer to any applicable terms of use of the publisher.

\section{General rights}

Copyright for the publications made accessible via the Queen's University Belfast Research Portal is retained by the author(s) and / or other copyright owners and it is a condition of accessing these publications that users recognise and abide by the legal requirements associated with these rights.

Take down policy

The Research Portal is Queen's institutional repository that provides access to Queen's research output. Every effort has been made to ensure that content in the Research Portal does not infringe any person's rights, or applicable UK laws. If you discover content in the Research Portal that you believe breaches copyright or violates any law, please contact openaccess@qub.ac.uk. 
Psychological Adjustment to Type 2 Diabetes and Relationship Quality

$$
\text { M Dempster }{ }^{1}, \text { T McCarthy }^{2}, \text { M Davies }^{3}
$$

${ }^{1}$ School of Psychology, Queen's University Belfast

${ }^{2}$ Western Health \& Social Care Trust, Northern Ireland

${ }^{3}$ Belfast Health \& Social Care Trust, Northern Ireland

Correspondence to:

Martin Dempster

School of Psychology, Queen's University Belfast, University Road,

Belfast BT7 1NN

m.dempster@qub.ac.uk

Tel: 02890975547

Fax: 02890975486

Running head: Relationship Quality and Psychological Adjustment to Type 2

Diabetes

\section{Acknowledgements}

We would like to acknowledge the contribution of Dr Roy Harper and Dr Janet Harding (Consultant Physicians), who facilitated the study. 


\section{Summary}

Aims. To examine the associations between psychological adjustment to Type 2 Diabetes and the reported quality and type of relationships with partners Methods. All participants $(\mathrm{n}=88)$ completed a number of questionnaires including two measures of relationship quality: the Dyadic Adjustment Scale and the Personal Assessment of Intimacy in Relationships Scale, the Diabetes Quality of Life Scale and the ATT-19 (which assesses personal integration of diabetes). Additionally, HbA1c levels were obtained from medical notes.

Results. Measures of relationship quality significantly contributed to the explanation of two outcomes: personal integration of diabetes and satisfaction with the burden of self-management behaviours. More specifically, the findings demonstrate that a specific aspect of relationship quality - intimacy in recreational activities - is positively associated with the outcomes mentioned above.

Conclusions. People with Type 2 Diabetes who are not taking insulin, who share engagement in physical activities with their partner are more likely to be psychologically well-adjusted to their diagnosis of diabetes.

Keywords: Type 2 Diabetes, health-related quality of life, psychological adjustment, spouse 


\section{Introduction}

For those diagnosed with diabetes, the changes necessary to establish and maintain good metabolic control can require wide-ranging lifestyle adjustments in terms of food purchased, diet, glucose monitoring, activity levels and medication. Since Type 2 Diabetes often occurs later in life, it is likely that many people with Type 2 Diabetes will already have established close relationships. Consequently, in the majority of cases, the lifestyle changes necessary for management of Type 2 Diabetes will impact upon couples, if not families, and will necessitate a reorganisation of existing close relationships.

Relationships can affect an individual's vulnerability to illness, the impact of that illness, recovery from illness, mortality levels and even the utilisation of hospital services (1). Family stress and marital satisfaction has been found to contribute to overall health, immune system functioning (2) and endocrine functioning (3). Various characteristics of the family unit have been correlated with outcome in a range of illnesses, including chronic fatigue (4), schizophrenia (5), cancer (6) and cardiovascular illnesses (7).

A considerable amount of research has examined the role of the family in relation to health-related outcomes among people with Type 1 Diabetes (eg. 8,9). However, this research tends to focus on adolescents or young adults. Given that Type 2 Diabetes is more likely than Type 1 Diabetes to onset later in life, the nature of the relationships formed by people with Type 2 Diabetes are often different from those formed by people with Type 1 Diabetes.

Among adults with Type 2 Diabetes it has been shown that family support, and spousal support in particular, are associated with positive self-management 
behaviours in general (10) and with dietary behaviour specifically $(11,12)$. However, there is research to suggest that close relationships can also impact negatively on diabetes-related outcomes $(13,14)$. This negative impact is often the result of the person with diabetes feeling "over-protected" by close family members $(15,16)$. Therefore, it is important to explore whether the nature of close relationships can impact on diabetes-related outcomes and, more specifically, there is a need to examine the associations between close relationships and psychological outcomes that have been shown to be related to self-management behaviours (17).

The only previous research which has sought to address this need is a series of studies conducted by Trief and colleagues (18-21). Nevertheless, this series of studies included as participants a group of people with diabetes who were taking insulin they did not discriminate between people with Type 1 Diabetes and Type 2 Diabetes and they did not include people who were not taking insulin. Furthermore, the relationship quality measures used in these studies provided an overall assessment of relationship quality rather than being separated into different dimensions of relationship quality to allow an exploration of how the nature of the relationship is associated with outcomes.

There is no previous research which has examined the association between relationship quality and diabetes-related outcomes among people with Type 2 Diabetes who are not taking insulin. It is reasonable to assume that the impact of managing Type 2 Diabetes will differ among those who take insulin and those who do not. People with diabetes who take insulin (and their family members) need to deal with the adverse effects of taking too much or too little insulin and the daily impact of self management of insulin administration. In fact, although Type 1 and Type 2 Diabetes are valid distinctions in medical terms, it has been argued that insulin 
treatment is the major dichotomy in psychological and behavioural terms and this dichotomy has implications for adaptation and quality of life (19).

The present study, therefore, aims to address the gap by examining the nature of the associations between relationship quality and diabetes-related outcomes (health-related quality of life, blood glucose levels (HbA1c) and personal integration of diabetes) among adults with Type 2 Diabetes who are not taking insulin.

\section{Patients and Methods}

Participants were identified from the caseload of 2 Consultant Diabetologists, within a Health and Social Care Trust. Patients were selected from a database if they met the following inclusion criteria: diagnosed within the last 5 years, diagnosis of Type 2 Diabetes, and not currently prescribed insulin. A final inclusion criterion, that patients are married or cohabiting for longer than one year, could not be determined from the database. All participants with Type 2 Diabetes who were not taking insulin on the database $(\mathrm{n}=482)$ were posted questionnaires. A total of $88 / 482$ participants returned completed questionnaires. However, as it was not possible to determine from the database if potential participants were in a relationship, the total number of questionnaires posted also includes people who did not meet all of the inclusion criteria. In addition, a physiological measure of blood glucose control (HbA1c) was obtained for each participant from medical notes. The questionnaires administered were:

The Personal Assessment of Intimacy in Relationships Scale (PAIR). The PAIR (22) is a 36 item self-report measure. It examines relationship intimacy on several domains: emotional, social, sexual, intellectual and recreational. High scores 
on the emotional scale indicate that the person experiences closeness of feeling, supportiveness and genuine understanding from his/her partner; high scores on the social scale indicate that the person shares a social network with his/her partner; high scores on the sexual scale indicate that the person experiences physical closeness and/or sexual activity with their partner; high scores on the intellectual scale indicate that the person shares ideas and discussions with his/her partner; high scores on the recreational scale indicates that the person and their partner share involvement in leisure activities. The PAIR has been shown to be internally consistent for all domains, having a Cronbach's alpha greater than 0.70 . The PAIR has been used previously among adults with Type 2 Diabetes (19).

The Dyadic Adjustment Scale (DAS). The DAS (23) is a 32 item self-report measure, which separates into 4 dimensions: satisfaction, consensus, cohesion, and affectional expression. High scores on the satisfaction scale indicates a lack of conflict in the person's relationship with their partner; high scores on the consensus scale indicates that the person and their partner most often agree on a range of topics; high scores on the cohesion scale indicate that the person regularly engages in activities (intellectual and leisure) with their partner; high scores on the affectional expression scale indicate that the person regularly experiences physical closeness with their partner. All Cronbach's alpha values for the subscales are greater than 0.7. The DAS has been used previously among adults with Type 2 Diabetes (19).

The Diabetes Quality of Life Scale (DQOL). The DQOL (24) is a 46 item selfreport scale. It possesses three diabetes-specific subscales: satisfaction, impact and worry. High scores on the satisfaction scale relate to high levels of satisfaction with the potential burden caused by self-management behaviours and satisfaction with social and physical functioning; high scores on the impact scale indicate low 
frequency of adverse events related to diabetes and infrequent restrictions or interruptions to social and physical functioning; high scores on the worry scale indicate that the person is unlikely to worry about the effect of diabetes on their social and physical functioning. The DQOL has evidence for validity, as demonstrated by moderate to strong correlations with other measures of QoL (25) and Cronbach's alpha values are high for the separate domains. Higher scores on all domains represent better domain-specific quality of life.

The Diabetes Integration Scale (ATT-19). The ATT-19 (26) is a shortened version of the ATT-39 (27) which is a measure of psychological adjustment to diabetes. The ATT-19 is a 19 item self-report scale. Welch et al. (26) suggest that the ATT-19 scale shows good concurrent and construct validity, internal reliability and discriminant validity. Higher scores on the scale indicate that the individual is more accepting of their diabetes and is more likely to be well adjusted to their diabetes.

Ethical approval was obtained from the local Medical Ethics Committee.

Statistical Analysis

Correlations between the demographic/medical variables and the relationship quality measures (the PAIR and the DAS scales) and the outcome measures (the HbA1c values, ATT-19 and DQOL scales) were generated using Pearson's correlation coefficients in all cases except when gender or reported number of comorbidities was one of the variables in the correlated pair. When gender was included, a biserial correlation coefficient was generated and when number of comorbidities was included, Spearman's rho correlation coefficient was calculated. 
To model the relationships between the outcome measures which showed some significant relationships with potential covariates on the basis of the correlation coefficients (i.e. the DQOL satisfaction and ATT-19 scales) and the relationship quality scales (as assessed by the PAIR), after taking account of the demographic/medical variables, two hierarchical regression analyses were conducted, with the demographic/medical variables entered as the first block and the PAIR scales entered as the second block.

\section{Results}

A total of 88 complete responses were obtained. Almost 55\% (48/88) of the 88 participants were men and 93\% (82/88) of the participants were married. Other descriptive statistics are presented in Table 1. The results indicate that the participants, on average, score above the midpoint on measures of relationship quality, except for affectional expression. Scores are particularly high for the DAS scales of consensus and satisfaction and the PAIR emotional scale. With respect to outcome measures, participants have, on average, $\mathrm{HbA1c}$ within the normal range, are well adjusted to their diabetes and have good diabetes-related quality of life.

Correlations between the PAIR and DAS subscales and the outcome measures (ATT-19, DQoL and HbA1c) are presented in Table 2. The demographic variables were not significantly related to any of the outcome measures, with one exception - as the reported number of comorbidities increased, the scores on the DQOL satisfaction scale decreased. None of the relationship quality variables showed a statistically significant relationship with HbA1c levels or the DQOL scales of impact or worry. Furthermore, none of the DAS scales were significantly related to any of the outcome measures. However, the emotional, sexual and recreational scales of the PAIR 
demonstrated significant, positive relationships with the DQoL satisfaction scale and the ATT-19. The PAIR intellectual scale also had a significant, positive correlation with the ATT-19.

The regression model presented in Table 3 explained 38\% of the variance in the DQOL satisfaction scale (adjusted $\mathrm{R}^{2}=0.28 ; \mathrm{F}(12,74)=3.821, \mathrm{p}<.001$ ). The demographic variables explained $23 \%$ of the variance, with the PAIR scales contributing the remaining $15 \%$.

The regression model presented in Table 4 explained $25 \%$ of the variance in the ATT-19 scale (adjusted $\mathrm{R}^{2}=0.13 ; \mathrm{F}(12,73)=2.065, \mathrm{p}=.030$ ). The demographic variables explained $6 \%$ of the variance, with the PAIR scales contributing the remaining 19\%. In both regression models, the PAIR recreational scale was a significant covariate.

\section{Discussion}

This study aimed to assess whether the nature and quality of close relationships were associated with quality of life, glycaemic control and adjustment to diabetes in people with Type 2 Diabetes who were not taking insulin. In summary, the results show that relationship quality (as assessed by the PAIR) significantly contributes to the explanation of satisfaction with the burden of self-management behaviours and the effect of diabetes on personal life (as assessed by the DQOL satisfaction scale) and personal integration of diabetes (as assessed by the ATT-19). The number of comorbidities also impacts on the level of satisfaction with the impact of diabetes on the person's life. 
More specifically, the findings demonstrate that a specific aspect of relationship quality - intimacy in recreational activities - is positively associated with the outcomes mentioned above. In effect, this means that the people in our sample who were more likely to believe that they engaged in shared leisure pursuits with their partner were also more likely to be well-adjusted to their diabetes (in that they were more satisfied with the impact of diabetes on their life and be more accepting of their diabetes). The association appears to be specific to active leisure activities, as neither a significant or strong association was found between measures of adjustment and shared intellectual activities (as assessed by the PAIR intellectual scale) or shared activities of any type (as assessed by the DAS cohesion scale).

The relationship between adjustment and leisure pursuits may be explained in at least two ways. Firstly, frequent engagement in leisure pursuits with their partner may simply be an indicator of frequent activity for the person with diabetes and research demonstrates that engagement in physical activity is associated with better psychological health among people with Type 2 Diabetes $(28,29)$.

Secondly, active leisure pursuits are one of the areas of life most likely to be affected by diabetes. If these activities are shared with the partner, then perhaps this engenders within the partner a better understanding of the effect that diabetes has on the person's life and an active encouragement to make any adjustments that need to be made to allow the person with diabetes to continue with these activities. This explanation suggests that a partner is closely involved at the personal level in sharing recreational activities with the person with diabetes, rather than simply being present during these activities. In other words, this suggests a level of engagement during recreational activities which is only likely to be found with someone with whom the person with diabetes shares a close, personal and meaningful relationship. This notion 
of a level of involvement that implies a more intimate relationship is what is being assessed by the PAIR. In other words, the items on the PAIR scale do not assess whether partners engage in recreational activities together but whether they enjoy and share together at a deeper level their engagement in recreational activities. This explanation suggests that partners in this situation are unlikely to over-protect the person with diabetes, thereby avoiding one of the main perceived drawbacks of close family support $(15,16)$. If this explanation is likely to be true, then it would also be likely that the partner will have a similar understanding of diabetes and its effects as the person with diabetes. Indeed, the congruence between the representations of diabetes held by the patient and their partner have been shown to be important predictors of self-management behaviour (30) and blood sugar level control (31), but there is no research examining the congruence of beliefs about diabetes and its association with quality of life or quality of relationships.

Having more comorbidities led to less satisfaction with the impact of diabetes on quality of life but was not associated with personal integration of diabetes. This suggests that having additional comorbidities does not impact on the person's psychological adjustment to diabetes but does impact on their perceived burden of self-care. Our sample was not large enough to consider the type of comorbidities but such an analysis might provide further insights. For example, it might be the case that people who have other conditions which also require a portion of time to be spent in treatment (eg. kidney dialysis) find that the additional burden imposed by selfmanagement of diabetes is detrimental to their life quality.

Nevertheless, relationship quality, and intimacy in recreational activities specifically, added significantly to the explanation of quality of life and personal integration of diabetes even after considering the demographic and medical variables 
assessed in this study. The findings therefore suggest a need for psychosocial interventions in Type 2 Diabetes to consider the role of the partner.

Relationship quality in this study did not explain blood sugar levels (as assessed by HbA1c). A similar finding has been noted previously (19) and in the present study the small variation in levels of blood sugar across participants is a potential explanation for the lack of association.

In the present study, scales on the PAIR were stronger correlates of the outcome measures than scales on the DAS. In previous research among people with diabetes, the PAIR and the DAS were found to contribute similarly to the explanation of quality of life $(19,20)$. However, in these studies only total scores were used rather than the separate scales of the questionnaires and the sample was a mixture of people with Type 1 and Type 2 Diabetes. Therefore, we conclude that the dimensions of relationship quality assessed by the PAIR are more appropriate than the DAS in explaining adjustment among adults with Type 2 Diabetes who are not taking insulin.

There are limitations to the generalisations that can be made on the basis of this study, which primarily result from the relatively small sample size. Given the sample size, it is inappropriate to dismiss variables as unimportant in explaining adjustment to diabetes simply because they did not show a statistically significant relationship in this study. However, our findings point towards the most salient variables among those assessed.

Additionally, it is unclear to what extent our sample represents the population of people with Type 2 Diabetes who are not taking insulin. As is often the case in studies that use this design, it is not possible to obtain information on those who did not respond to the request to participate. Therefore, it is important to clarify that our sample is a generally well adjusted group of individuals with Type 2 Diabetes who are 
not taking insulin, who attend a hospital-based diabetes clinic rather than attending primary care services only and who are currently in a heterosexual relationship. The implications of this research are, therefore, limited to a population defined by these characteristics.

In conclusion, the findings of the present study suggest that active interactions within couples in a relationship may offer a positive effect in relation to diabetesrelated outcomes. The nature of the associations highlighted in the present study is important information for health professionals involved in diabetes education programmes.

Declaration of competing interests: Nothing to declare 


\section{References}

1. Robles TF, Kiecolt-Glaser JK. The physiology of marriage: pathways to health. Physiol Behav 2003; 79: 409-416.

2. Kiecolt-Glaser JK, Malarkey WB, Chee M, Newton T, Cacioppo TJ, Mao H. Negative behaviour during marital conflict is associated with immunological downregulation. Psychosom Med 1993; 55: 395-409.

3. Kiecolt-Glaser JK, Newton T, Cacioppo JT, MacCallum RC, Glaser R, Malarkey WB. Marital conflict and endocrine function: are men really more physiologically affected than women? J Consult Clin Psychol 1996; 64: 324-332.

4. Goodwin SS. The marital relationship and health in women with chronic fatigue and immune dysfunction syndrome: views of wives and husbands. Nurs Res 1997; 46: 138-146.

5. Erickson DH, Beiser M, Iacono WG. Social support predicts 5-year outcome in first-episode schizophrenia. J Abnormal Psychol 1998; 107: 681-685.

6. Feldman B, Broussard CA. The influence of relational factors on men's adjustment to their partners' newly-diagnosed breast cancer. J Psychosocial Oncol 2006; 23: 23 43. 
7. Haynes SG, Feinleib M, Kannel WB. The relationship of psychosocial factors to coronary heart disease in the Framingham Study: Eight year incidence of coronary heart disease. Am J Epidemiol 1980; 111: 37-58.

8. Cardenas L, Vollbona C, Baker S, Yusim S. Adult onset diabetes mellitus, glycemic control and family function. Am J Med Sci 1987; 293: 28-33.

9. Williams LB, Laffel LMB, Hood KK. Diabetes-specific family conflict and psychological distress in paediatric Type 1 diabetes. Diabet Med 2009; 26: 908-914.

10. Beverly EA, Wray LA. The role of collective efficacy in exercise adherence: a qualitative study of spousal support and Type 2 diabetes management. Health Educ Res 2010; 25: 211-223.

11. Choi SE. Diet-specific family support and glucose control among Korean immigrants with Type 2 diabetes. Diabetes Educator 2009; 35: 978-985.

12. Miller D, Brown JL. Marital interactions in the process of dietary change for type 2 diabetes. J Nutr Educ Behav 2005; 37: 226-234.

13. Carter-Edwards L, Skelly AH, Cagle CS, Appel SJ. "They care but don't understand"': Family support of African American women with type 2 diabetes. Diabetes Educator 2004; 30: 493-501. 
14. Jones RA, Utz SW, Williams IC, Hinton I, Alexander G, Moore C, Blankenship J, Steeves R, Oliver N. Family interactions among African Americans diagnosed with type 2 diabetes. Diabetes Educator 2008; 34: 318-326.

15. DeRidder DTD, Schreurs KMG, Kuijer RG. Is spousal support always helpful to patients with asthma or diabetes? A prospective study. Psychol Health 2005; 20: $497-$ 508.

16. Hagedoorn M, Keers JC, Links TP, Bouma J, Ter Maaten JC, Sanderman R. Improving self-management in insulin-treated adults participating in diabetes education. The role of overprotection by the partner. Diabet Med 2006; 23: 271-277.

17. Maddigan SL, Majumdar SR, Johnson JA. Understanding the complex associations between patient-provider relationships, self-care behaviours, and healthrelated quality of life in Type-2 diabetes: a structural equation modeling approach. Qual Life Res 2005; 14: 1489-1500.

18. Trief PM, Grant W, Elbert K, Weinstock RS. Family environment, glycemic control, and the psychosocial adaptation of adults with diabetes. Diabetes Care 1998; 21: $241-245$.

19. Trief PM, Himes CL, Orendorff R, Weinstock RS. The marital relationship and psychosocial adaptation and glycemic control of individuals with diabetes. Diabetes Care 2001; 24: 1384-1389. 
20. Trief PM, Wade MJ, Britton KD, Weinstock RS. A prospective analysis of marital relationship factors and quality of life in diabetes. Diabetes Care 2002; 25: 11541158.

21. Trief PM, Ploutz-Snyder R, Britton KD, Weinstock RS. The relationship between marital quality and adherence to the diabetes care regimen. Ann Behav Med 2004; 27: $148-154$

22. Schafer MT, Olson DH. Assessing intimacy: the PAIR Inventory. J Marriage Fam Therapy 1981; 7: 47-60.

23. Spanier GB. Measuring dyadic adjustment; new scales for assessing the quality of marriage and similar dyads. J Marriage Fam 1976; 38: 15-27.

24. The Diabetes Control and Complications Trial Research Group. Reliability and validity of a diabetes quality of life measure for the Diabetes Control and Complications Trial. Diabetes Care 1988; 11: 725-732.

25. Jacobson AA, Samson JA, DeGroot M. The evaluation of two measures of quality of life in patients with type 1 and type 2 diabetes. Diabetes Care 1994; 17: 267-274.

26. Welch G, Dunn SM, Beeney LJ. The ATT39: A measure of psychological adjustment to diabetes. In Bradley C ed. Handbook of Psychology and Diabetes. Switzerland: Harwood Academic Publishers 1994. 
27. Dunn SM, Smartt H, Beeney L, Turtle J. Measurement of emotional adjustment in diabetic patients: Validity and reliability of the ATT39. Diabetes Care 1986; 9: 480489.

28. Biddle SJH, Mutrie N. Psychology of Physical Activity: Determinants, Well-being and Interventions. New York: Routledge 2008.

29. Delahanty LM, Conroy MB, Nathan DM. Psychological predictors of physical activity in the diabetes prevention program. J Am Dietetic Assoc 2006; 106: 698-705.

30. Searle A, Norman P, Thompson R, Vedhara K. Illness representations among patients with type 2 diabetes and their partners: Relationships with self-management behaviours. J Psychosom Res 2007; 63: 175-184.

31. White P, Smith SM, Hevey D, O’Dowd T. Understanding Type 2 Diabetes: Including the family member's perspective. Diabetes Educator 2009; 35: 810-817. 
Table 1: Participant Characteristics

\begin{tabular}{|c|c|c|}
\hline & Mean (SD) & $\begin{array}{l}\text { Potential Range } \\
\text { (Midpoint) }\end{array}$ \\
\hline Age (years) & $61.60(10.9)$ & - \\
\hline Years married/with partner & $33.39(13.9)$ & - \\
\hline Months since diagnosis & $26.32(15.5)$ & - \\
\hline Reported number of comorbidities & $1(2)^{*}$ & - \\
\hline PAIR emotional & $18.43(4.80)$ & $0-24(12)$ \\
\hline PAIR social & $16.07(4.69)$ & $0-24(12)$ \\
\hline PAIR sexual & $16.13(5.42)$ & $0-24(12)$ \\
\hline PAIR intellectual & $16.99(4.31)$ & $0-24(12)$ \\
\hline PAIR recreational & $15.53(4.61)$ & $0-24(12)$ \\
\hline DAS consensus & $51.90(7.75)$ & $0-65(32.5)$ \\
\hline DAS satisfaction & $39.26(5.90)$ & $0-53(26.5)$ \\
\hline DAS affectional expression & $9.20(2.64)$ & $0-20(10)$ \\
\hline DAS cohesion & $14.30(4.74)$ & $0-24(12)$ \\
\hline DQoL satisfaction & $72.48(10.09)$ & $0-100(50)$ \\
\hline DQoL impact & $75.12(9.89)$ & $0-100(50)$ \\
\hline DQoL worry & $79.78(22.28)$ & $0-100(50)$ \\
\hline ATT-19 & $67.90(8.0)$ & $19-95(57)$ \\
\hline \multirow[t]{2}{*}{$\mathrm{HbA1c}$} & $7.0(1.0) \%$ & - \\
\hline & $53(10) \mathrm{mmol} / \mathrm{mol}$ & \\
\hline
\end{tabular}

* Median (interquartile range) values presented rather than mean (SD) values 
Table 2: Correlation coefficients (and p values) between demographic variables, marital relationship variables and outcomes

\begin{tabular}{|c|c|c|c|c|c|}
\hline & DQOL & DQOL & $\overline{\text { DQOL }}$ & ATT-19 & hbA1c \\
\hline & satisfaction & Impact & Worry & & \\
\hline \multirow[t]{2}{*}{ Gender } & -.080 & .098 & .023 & -.052 & .010 \\
\hline & $(.456)$ & $(.366)$ & $(.829)$ & $(.634)$ & $(.924)$ \\
\hline \multirow[t]{2}{*}{ Age } & .033 & -.064 & .161 & .145 & -.053 \\
\hline & $(.761)$ & $(.544)$ & $(.135)$ & $(.184)$ & $(.625)$ \\
\hline Years married & -.170 & -.162 & .109 & .001 & -.006 \\
\hline /with partner & $(.133)$ & $(.152)$ & $(.336)$ & $(.998)$ & $(.959)$ \\
\hline Months since & -.148 & -.105 & -.022 & -.087 & .103 \\
\hline diagnosis & $(.177)$ & $(.338)$ & $(.840)$ & $(.431)$ & $(.353)$ \\
\hline Reported & -.431 & -.106 & -.198 & .018 & .013 \\
\hline number of & $(<.001)$ & $(.327)$ & $(.064)$ & $(.867)$ & $(.908)$ \\
\hline \multicolumn{6}{|l|}{ comorbidities } \\
\hline \multirow[t]{2}{*}{ DAS consensus } & .107 & -.066 & .052 & .029 & -.012 \\
\hline & $(.320)$ & $(.539)$ & $(.627)$ & $(.790)$ & $(.910)$ \\
\hline DAS & .166 & .121 & .043 & .148 & -.032 \\
\hline satisfaction & $(.122)$ & $(.263)$ & $(.694)$ & $(.171)$ & $(.771)$ \\
\hline DAS affectional & .169 & .130 & .091 & .113 & -.049 \\
\hline expression & $(.116)$ & $(.227)$ & $(.400)$ & $(.299)$ & $(.650)$ \\
\hline \multirow[t]{2}{*}{ DAS cohesion } & .126 & .010 & -.075 & .081 & -.049 \\
\hline & $(.241)$ & $(.929)$ & $(.490)$ & $(.455)$ & $(.652)$ \\
\hline \multirow[t]{2}{*}{ PAIR emotional } & .230 & .158 & .005 & .278 & -.061 \\
\hline & $(.031)$ & $(.142)$ & $(.960)$ & $(.009)$ & $(.572)$ \\
\hline
\end{tabular}




\begin{tabular}{llllll}
\hline PAIR social & .084 & .113 & -.021 & .111 & -.071 \\
& $(.439)$ & $(.295)$ & $(.844)$ & $(.304)$ & $(.515)$ \\
PAIR sexual & $\mathbf{. 3 2 1}$ & .142 & .003 &. $\mathbf{2 3 7}$ & -.026 \\
& $\mathbf{( . 0 0 2 )}$ & $(.186)$ & $(.976)$ & $\mathbf{( . 0 2 7})$ & $(.812)$ \\
PAIR & .167 & .098 & -.029 & $\mathbf{. 2 6 1}$ & -.039 \\
intellectual & $(.120)$ & $(.363)$ & $(.790)$ & $\mathbf{( . 0 1 4 )}$ & $(.717)$ \\
PAIR & $\mathbf{. 3 1 8}$ & .130 & -.003 & $\mathbf{. 3 1 5}$ & -.036 \\
recreational & $\mathbf{( . 0 0 3 )}$ & $(.226)$ & $(.981)$ & $\mathbf{( . 0 0 3 )}$ & $(.741)$ \\
\hline
\end{tabular}

For $\mathrm{n}=88, \mathrm{p}=0.05$ when $\mathrm{r}=0.21$ and $\mathrm{p}=0.01$ when $\mathrm{r}=0.34$, using a two-tailed test 
Table 3: Regression model with DQOL Satisfaction as the outcome variable

\begin{tabular}{cccc}
\hline Unstandardised & Standardised & & \\
Coefficient & Coefficient & & $\mathrm{p}$ \\
& & & \\
\hline 58.124 & & 4.845 & $<.001$ \\
-2.350 & -.081 & -.813 & .419 \\
.314 & .236 & 1.857 & .067
\end{tabular}

Years married/with

$\begin{array}{llll}-.215 & -.195 & -1.538 & .128\end{array}$

partner

Months since diagnosis $\begin{array}{llll}-.020 & -.020 & -.206 & .838\end{array}$

No comorbidities vs 1

$-6.181$

$\begin{array}{lll}-.204 & -1.476 \quad .144\end{array}$

No comorbidities vs 2

$-8.124$

$-.222$

$-1.813 \quad .074$

No comorbidities vs 3

or more

$\begin{array}{llll}-15.789 & -.472 & -3.744<.001\end{array}$

PAIR emotional

$\begin{array}{llll}-.105 & -.035 & -.229 & .820\end{array}$

PAIR social

$-.314$

$-.101$

$-.907 \quad .367$

PAIR sexual .561

.209

$1.375 \quad .173$

PAIR intellectual $-.291$ $-.085 \quad-.504 \quad .616$

PAIR recreational

1.259

.391

$2.896 \quad .005$ 
Table 4: Regression model with ATT-19 as the outcome variable

\begin{tabular}{cccc}
\hline Unstandardised & Standardised & & \\
Coefficient & Coefficient & & $\mathrm{p}$ \\
& & & \\
\hline 47.095 & & 5.149 & $<.001$ \\
-1.560 & -.077 & -.707 & .482 \\
.236 & .258 & 1.837 & .070
\end{tabular}

Years married/with

$\begin{array}{llll}-.115 & -.151 & -1.078 & .285\end{array}$

partner

Months since diagnosis

$\begin{array}{llll}-.016 & -.024 & -.218 & .828\end{array}$

No comorbidities vs 1

.765

$\begin{array}{lll}.036 \quad .835 & .815\end{array}$

No comorbidities vs 2

$-.193$

$-.008$

$-.056 \quad .955$

No comorbidities vs 3

or more

PAIR emotional .264

$\begin{array}{lll}.126 & .753 \quad .454\end{array}$

PAIR social

$-.356$

$\begin{array}{lll}-.167 & -1.348 & .182\end{array}$

PAIR sexual

$-.044$

$-.024$

$-.141 \quad .888$

PAIR intellectual

.260

.110

$.581 \quad .563$

PAIR recreational

.839

.378

$2.496 \quad .015$ 